\title{
Integration Host Factor Is Required for RpoN-Dependent $h r p L$ Gene Expression and Controls Motility by Positively Regulating rsmB sRNA in Erwinia amylovora
}

\author{
Jae Hoon Lee and Youfu Zhao
}

First and second authors: Department of Crop Sciences, University of Illinois at Urbana-Champaign, Urbana, IL 61801. Accepted for publication 10 September 2015 .

\begin{abstract}
Lee, J. H., and Zhao, Y. F. 2016. Integration host factor is required for RpoNdependent $h r p L$ gene expression and controls motility by positively regulating rsmB sRNA in Erwinia amylovora. Phytopathology 106:29-36.

Erwinia amylovora requires an hrp-type III secretion system (T3SS) to cause disease. It has been reported that $\mathrm{HrpL}$, the master regulator of T3SS, is transcriptionally regulated by sigma factor 54 (RpoN), YhbH, and HrpS. In this study, the role of integration host factor (IHF) in regulating $h r p L$ and T3SS gene expression was investigated. IHF is a nucleoid-associated protein that regulates gene expression by influencing

fruits. Growth of both mutants was greatly reduced, and expression of the $h r p L$ and T3SS genes was significantly down-regulated as compared with those of the wild type. In addition, expression of the ihfA, but not the ihfB gene, was under auto-suppression by IHF. Furthermore, both ihfA and ihf $B$ mutants were hypermotile, due to significantly reduced expression of small RNA (sRNA) rsmB. Electrophoresis mobility shift assay further confirmed that IHF binds to the promoters of the hrpL and ihfA genes, as well as the $r s m B$ sRNA gene. These results indicate that IHF is required for RpoN-dependent $h r p L$ gene expression and virulence, and controls motility by positively regulating the $r s m B$ sRNA in E. amylovora.
\end{abstract} nucleoid structure and DNA bending. Our results showed that both ihfA and $i h f B$ mutants of E. amylovora did not induce necrotic lesions on pear
Additional keywords: fire blight, Rsm/Csr system.
Erwinia amylovora, the causal agent of fire blight disease, is a worldwide threat to pome fruit industry. E. amylovora employs a hypersensitive response and pathogenicity ( $h r p)$-type III secretion system (T3SS) to translocate effector proteins directly into plant cells and modulate cell functions during infection (Zhao 2014). Expression of known components of the hrp-T3SS is regulated by the master regulator HrpL, a member of the exocytoplasmic functions (ECF) sigma factors (McNally et al. 2012; Wei and Beer 1995). As an alternative sigma factor belonging to the sigma 70 family, HrpL binds to the hrp box (GGAACC-N 16 -CCACNNA) at the -35 and -10 promoter regions of the target genes (Wei and Beer 1995). In turn, $h r p L$ transcription is controlled by another alternative sigma factor, sigma factor 54 (RpoN), along with its modulation protein $\mathrm{YhbH}$ and an enhancer binding protein (EBP) HrpS (Ancona et al. 2014; Ramos et al. 2013). HrpS, a member of the NtrC family, acts as an activator of RpoN-dependent transcription. However, the exact role of $\mathrm{YhbH}$, annotated as RpoN modulation protein, in $h r p L$ transcription remains unknown.

RpoN, initially identified for its role in nitrogen assimilation, binds to RNA polymerase (RNAP) and directs the RpoN-RNAP holoenzyme to specific promoter sites for transcription initiation in Escherichia coli (Bush and Dixon 2012; Hirschman et al. 1985; Hunt and Magasanik 1985). When the RpoN-RNAP holoenzyme binds to the consensus -24 (GG) and -12 (TGC) promoter regions, it forms a highly stable, transcriptionally silent closed complex, which requires energy input to promote transcription (Bush and Dixon 2012). To form an open complex for RpoN-dependent transcription, ATP hydrolysis by EBP provides the energy, thus

Corresponding author: Y. F. Zhao; E-mail address: zhao888@illinois.edu

*The $\boldsymbol{e}$-Xtra logo stands for "electronic extra" and indicates that one supplementary figure is published online.

http://dx.doi.org/10.1094/PHYTO-07-15-0170-R

(C) 2016 The American Phytopathological Society remodeling the holoenzyme (Bush and Dixon 2012). Since EBP usually binds to -80 to $-150 \mathrm{bp}$ upstream of the transcription start site, integration host factor (IHF) is often required to enhance the interaction between EBP and RpoN-RNAP holoenzyme (Huo et al. 2006; Schumacher et al. 2006).

Nucleoid-associated proteins (NAPs) are generally referred to small DNA-binding proteins that control nucleoid structure and gene expression via DNA looping, bending, wrapping or bridging in E. coli (Browning et al. 2010; Dillon and Dorman 2010). IHF is a bacterial NAP, which plays roles in nucleoid structuring, replication and DNA rearrangements (Gustave et al. 2013; Mangan et al. 2006). IHF is about $11 \mathrm{kDa}$ in size and predominantly exists in a heterodimeric form composed of IHF $\alpha$ and IHF $\beta$ subunits, encoded by the ihfA and ihfB genes, respectively. IHF binds to a well-conserved nucleotide sequence ((A/T)ATCAANNNNTT(A/G)) and introduce a U-turn up to $160^{\circ}$ into the DNA, thus acting like a transcription factor and being capable of allowing the interaction between EBP and RpoN-RNAP holoenzyme (Goodrich et al. 1990; Swinger and Rice 2004). IHF was first reported as a factor for the site-specific recombination of bacteriophage- $\lambda$ in $E$. coli (Miller and Friedman 1980 ) and has since been found to be involved in DNA replication, maintenance of nucloeid structure and transcription regulation (Dillon and Dorman 2010). IHF also influences growth kinetics of bacteria as intracellular abundance of IHF changes under different growth phases and reaches peak levels in the stationary phase (Ditto et al. 1994).

The requirement of IHF for virulence has been described in various bacterial species. Transcription of the invasion-specific genes, including virB and virF, was activated by IHF in Shigella flexneri (Porter and Dorman 1997). Expression of the major virulence genes responsible for epithelial cell invasion and systemic infection of the mouse was dependent on IHF in Salmonella enteric serovar Typhimurium (Mangan et al. 2006). The presence of IHF greatly induced the transcriptional activity of the $h r p L$ promoter in Pseudomonas syringae and Pectobacterium carotovorum subsp. 
carotovorum (Chatterjee et al. 2002; Jovanovic et al. 2011). In addition, it has been reported that the posttranscriptional regulatory system, composed of a RNA-binding protein RsmA/CsrA and a small noncoding regulatory RNA $r s m B / c s r B$, plays critical roles in virulence of many important pathogens (Ancona and Zhao 2013; Vakulskas et al. 2015). Interestingly, it has been recently shown that IHF acts as a positive regulator of $c s r B$ in $S$. typhimurium, suggesting a connection of IHF to the Csr system (Martínez et al. 2014). However, the role of IHF in E. amylovora virulence remains unknown.

Based on the genome sequence of E. amylovora ATCC 49946 (Sebaihia et al. 2010), two genes were annotated as ihfA (Eam_1633) and ihfB (Eam_1341), which have not been characterized (Supplementary Fig. S1). Our main goal in this study was to investigate the role of IHF in E. amylovora virulence and to determine whether IHF is required for the $\operatorname{rsmB}$ expression. Our results showed that IHF positively regulates $h r p L$ and other T3SS gene expression and is essential for E. amylovora virulence. Our results also demonstrated that IHF in E. amylovora is involved in the regulation of swimming motility by activating the expression of sRNA $r s m B$.

\section{MATERIALS AND METHODS}

Bacterial strains and growth conditions. The bacterial strains used in this study are listed in Table 1. Luria-Bertani (LB) medium was used for routine culture. Bacteria were also grown in hrp-inducing minimal medium (HMM) $\left(1 \mathrm{~g}\right.$ of $\left(\mathrm{NH}_{4}\right)_{2} \mathrm{SO}_{4}, 0.246 \mathrm{~g}$ of $\mathrm{MgCl}_{2} \cdot 6 \mathrm{H}_{2} \mathrm{O}, 0.099 \mathrm{~g}$ of NaCl, $8.708 \mathrm{~g}$ of $\mathrm{K}_{2} \mathrm{HPO}_{4}$, and $6.804 \mathrm{~g}$ of $\mathrm{KH}_{2} \mathrm{PO}_{4}$ ) with $10 \mathrm{mM}$ galactose (Ancona et al. 2014; Yang et al. 2014). When required, antibiotics were added to the medium at the following concentrations: chloramphenicol $(\mathrm{Cm})$ at $10 \mu \mathrm{g} \mathrm{ml}^{-1}$ and ampicillin (Ap) at $100 \mu \mathrm{g} \mathrm{ml}^{-1}$. Primer sequences used for mutant construction, mutant confirmation, quantitative real-time polymerase chain reaction (qRT-PCR), and cloning are available upon request.

Construction of $E$. amylovora mutants by Lambda-Red recombinase cloning. The ihfA and ihfB mutants of $E$. amylovora were generated using the $\lambda$ phage recombinase method as described previously (Datsenko and Wanner 2000; Zhao et al. 2009a). Briefly, overnight cultures of E. amylovora carrying pDK46 were subcultured in LB media containing $0.1 \%$ arabinose and grown to exponential phase $\left(\mathrm{OD}_{600}=0.8\right)$. Cells were made competent by washing with cold water and stored at $-80^{\circ} \mathrm{C}$. Recombination fragments consisting of $\mathrm{Cm}$ resistance gene $\left(\mathrm{Cm}^{\mathrm{r}}\right)$ flanked by a 50 -nucleotide homology arm were generated by PCR from pKD32 plasmid and introduced into the competent cells by electroporation. The resulting mutants were selected on LB plates supplemented with Ap and Cm, and the deletion mutations were confirmed by PCR amplification from internal region of $\mathrm{Cm}^{\mathrm{r}}$ gene to the external region of the target gene. The coding region of each gene in the mutants was replaced by $\mathrm{Cm}^{\mathrm{r}}$ gene, except for the first and last 50 nucleotides.

Cloning of genes for complementation. For complementation of the mutants, the promoter and coding sequences of the ihfA and $i h f B$ gene were amplified by PCR from the E. amylovora Ea1189 strain. The PCR fragments were cloned into pGEM T-easy vector (Promega) through A-T ligation according to the manufacturer's instruction. The final plasmids were designated as pIhfA and pIhfB, respectively, and introduced into the mutant strain by electroporation. The resulting transformants were selected on LB plates supplemented with Ap and $\mathrm{Cm}$. Plasmid DNA purification, PCR amplification of genes, and isolation of fragments from agarose gels were performed using standard molecular procedures (Sambrook and Russel 2001).

Bacterial growth in media. To measure bacterial growth, overnight cultures of E. amylovora wild type (WT), mutants, and complementation strains were harvested and resuspended in fresh medium $\left(\mathrm{OD}_{600}=0.01\right.$ for $\mathrm{LB}, \mathrm{OD}_{600}=0.2$ for $\left.\mathrm{HMM}\right)$. Bacterial strains were grown at $18^{\circ} \mathrm{C}(\mathrm{HMM})$ or $28^{\circ} \mathrm{C}(\mathrm{LB})$, and aliquots of the culture were taken at different time points during incubation. The bacterial growth for each strain was determined by measuring $\mathrm{OD}_{600}$. The experiments were repeated at least twice.

Virulence assay and bacterial growth on immature pear fruits. Overnight cultures of E. amylovora WT, mutants and complementation strains were harvested and resuspended in PBS to $\mathrm{OD}_{600}=0.001$. Immature Bartlett pear fruits (Pyrus communis L. 'Bartlett') were used for virulence assays, while immature Asian pear fruits were used for bacterial growth assays (Wang et al. 2010). Pears were surface-sterilized with $10 \%$ bleach, pricked with a sterile needle, and inoculated with $2 \mu$ of cell suspensions for each

TABLE 1. Bacterial strains, plasmids, and probe sequences used in this study ${ }^{\mathrm{a}}$

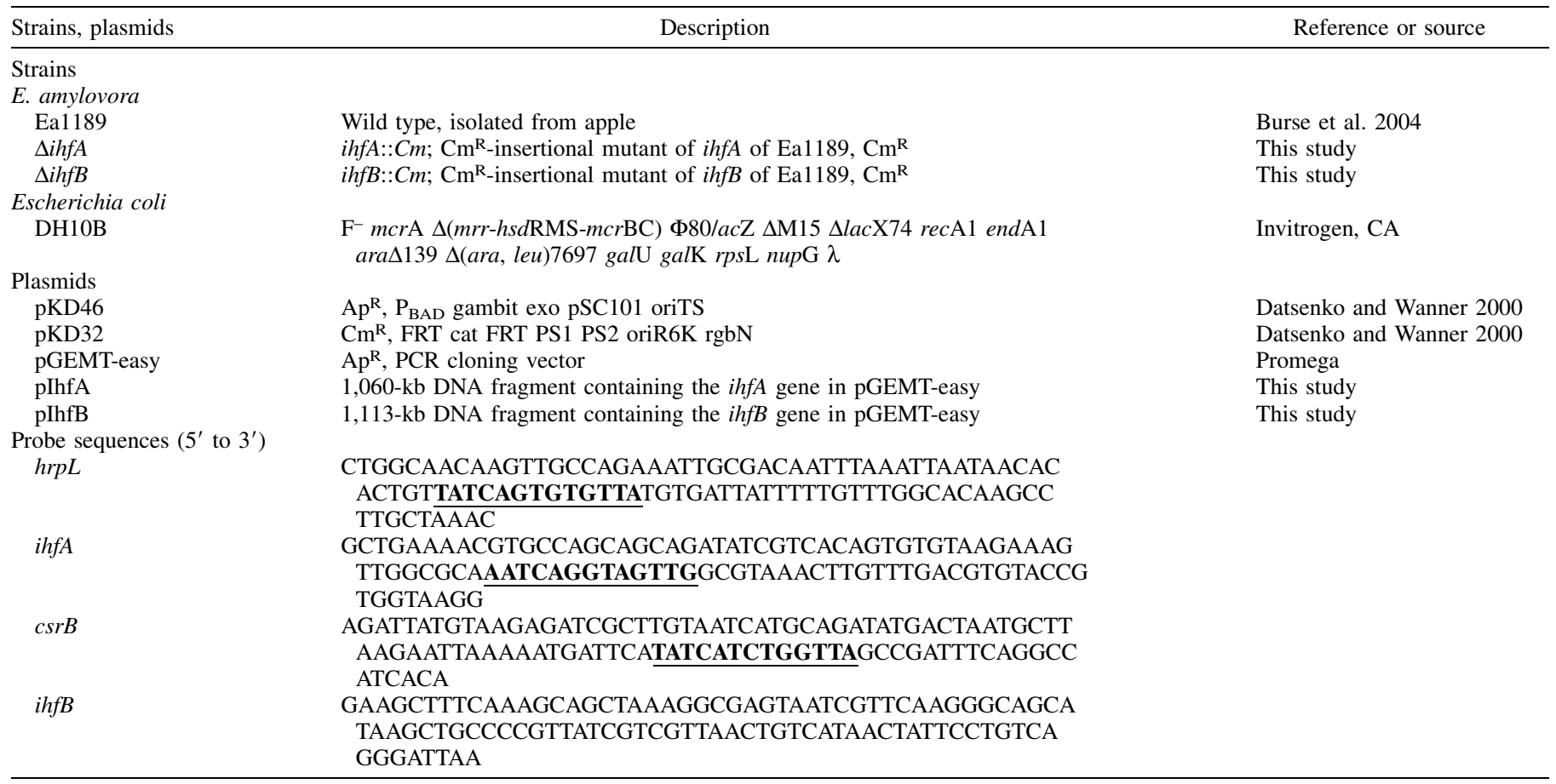

${ }^{a}$ Bold and underlined sequences indicate the potential IHF binding sites. Ap, ampicillin; Cm, chloramphenicol. 
strain. Symptoms were recorded at 4 and 8 days postinoculation (DPI) in virulence assays. For bacterial growth studies, the pear tissues surrounding the inoculation site was excised using a No. 4 cork borer and homogenized in $1 \mathrm{ml}$ of PBS. Bacterial growth from 1 to 3 DPI was monitored by dilution plating on LB medium supplemented with appropriate antibiotics. For each strain tested, fruits were assayed in triplicate, and the experiments were repeated at least twice.

Swimming motility assay. The motility of each strain was determined by measuring diameters on the motility agar plates ( $10 \mathrm{~g}$ of tryptone, $5 \mathrm{~g}$ of $\mathrm{NaCl}$, and $2.5 \mathrm{~g}$ of agar per liter) as previously described (Zhao et al. 2009b). Briefly, overnight cultures of E. amylovora WT, mutants, and complementation strains were harvested, washed, and resuspended in PBS to $\mathrm{OD}_{600}=1$. Bacterial cells were then plated onto the center of agar plates, and diameters were determined at 24 and $48 \mathrm{~h}$ postinoculation. The experiments were repeated at least twice.

RNA isolation. Bacterial cultures grown overnight were harvested, washed twice, and resuspended in $\mathrm{HMM}$ to $\mathrm{OD}_{600}=$ 0.2 . After $6 \mathrm{~h}$ incubation in $\mathrm{HMM}$ at $18^{\circ} \mathrm{C}, 4 \mathrm{ml}$ of RNA protect reagent (Qiagen) was added to $2 \mathrm{ml}$ of bacterial cell culture and incubated at room temperature for $5 \mathrm{~min}$. RNA was extracted using the RNeasy Mini kit (Qiagen), following which the eluted total RNA was DNase-treated using Turbo DNA-free (Ambion) according to the manufacturer's instructions. For in vivo condition, overnight bacterial cultures were harvested, washed twice, and resuspended in PBS. Immature Bartlett pear fruits were surface-sterilized with $10 \%$ bleach, cut in half, and inoculated with bacterial suspension (Wang et al. 2012). After $6 \mathrm{~h}$ incubation at $28^{\circ} \mathrm{C}$ in a moist chamber, bacterial cells were collected by washing pear surfaces with a solution containing $2 \mathrm{ml}$ of RNA protect reagent (Qiagen) and $1 \mathrm{ml}$ of water, and RNA was extracted as described above. Quality and quantity of the RNA was assessed using a Nano-Drop ND-100 spectrophotometer (Nano-Drop Technologies).

qRT-PCR. Reverse transcription for cDNA synthesis was performed using Superscript VILO cDNA synthesis kit (Invitrogen) on $1 \mu \mathrm{g}$ of total RNA according to the manufacturer's instruction. The $100 \mathrm{ng}$ of reverse transcription product was used for qRT-PCR analysis in a total volume of $20 \mu \mathrm{l}$, containing $10 \mu \mathrm{l}$ of Power SYBR Green PCR master mix (Applied Biosystems), primers of selected genes $(500 \mathrm{nM})$, and water. The qRT-PCR program was $50^{\circ} \mathrm{C}$ for $2 \mathrm{~min}, 95^{\circ} \mathrm{C}$ for $10 \mathrm{~min}$, followed by 40 cycles of $95^{\circ} \mathrm{C}$ for $15 \mathrm{~s}$ and $60^{\circ} \mathrm{C}$ for $1 \mathrm{~min}$, and a final dissociation curve analysis step from 65 to $95^{\circ} \mathrm{C}$. Gene expression levels were analyzed using the relative quantification $(\Delta \Delta \mathrm{Ct})$ method, and a $16 \mathrm{~S}$ rDNA ( $r r s A)$ gene was used as an endogenous control to normalize gene expression data.

Electrophoretic mobility shift assay (EMSA). Complementary oligonucleotides containing the upstream regions of the $i h f A$, ihfB, hrpL, and $r s m B$ sRNA were 3 ' biotinylated using the biotin $3^{\prime}$ end DNA labeling kit (Pierce). Probe sequences were listed in Table 1. For annealing, equal amounts of the end-labeled, complementary oligonucleotides were mixed together and incubated at room temperature for $1 \mathrm{~h}$ before use. Increasing amount of E. coli IHF $\alpha \beta_{\mathrm{Ec}}$ (a gift from J. Gardner at the University of Illinois) was added in reaction volumes of $10 \mu \mathrm{l}$ containing $20 \mathrm{fmol}$ of labeled oligonucleotides, $1 \times$ binding buffer, $50 \mathrm{ng} \mu \mathrm{l}^{-1}$ Poly $(\mathrm{dI} \cdot \mathrm{dC}), 0.5 \mathrm{mM} \mathrm{MgCl} 2,0.1 \%$ Nonidet P-40, bovine serum albumin at $0.05 \mathrm{mg} \mathrm{ml}^{-1}$, and $5 \%$ glycerol. Reaction mixtures were incubated at room temperature for $20 \mathrm{~min}$, mixed with $2.5 \mu \mathrm{l}$ of $5 \times$ loading buffer, and resolved into a $6 \%$ native polyacrylamide gel in $0.5 \times$ TBE buffer ( $44.5 \mathrm{mM}$ Tris-base, $44.5 \mathrm{mM}$ boric acid, and $1 \mathrm{mM}$ EDTA). The resolved binding reactions were transferred to a positively charged nylon membrane and cross-linked. The chemiluminescent signals were developed according to the manufacturer's instructions from the lightshift chemiluminescent EMSA kit (Pierce) and visualized using ImageQuant LAS 4010 CCD camera (GE Healthcare).

\section{RESULTS}

Effect of $\boldsymbol{i h f}$ mutation on bacterial growth. To characterize the function of IHF in E. amylovora, single ihfA and ihfB knockout mutants were generated using the $\lambda$-Red cloning (Datsenko and Wanner 2000; Zhao et al. 2009a). However, despite repeated attempts, we were unable to obtain an ihfA/ihfB double mutant, possibly because that IHF is required for $\lambda$ recombination and pKD46 plasmid could not be maintained in the single mutant. In order to assess whether IHF plays a role in bacterial growth, two mutants and their complementation strains were tested for their abilities to grow in LB and HMM compared with E. amylovora WT strain. Both the ihfA and ihfB mutants grew much slower in LB in the early hours than that of WT, but reached similar level as the WT at $24 \mathrm{~h}$ postinoculation (Fig. 1A). No significant growth difference was observed between the WT and mutants in HMM (Fig. 1B). Complementation strains exhibited similar growth as the WT (Fig. 1). These results indicate that absence of either IHF subunit does not affect E. amylovora growth in nutrient-limited conditions, but suppresses growth under nutrient-rich conditions, suggesting that IHF might be required for rapid growth of E. amylovora under favorable conditions.

Mutations in $i h f A$ and $i h f B$ render E. amylovora nonpathogenic. To determine the role of IHF in E. amylovora virulence, WT, the ihfA and ihfB mutants and their complementation strains were

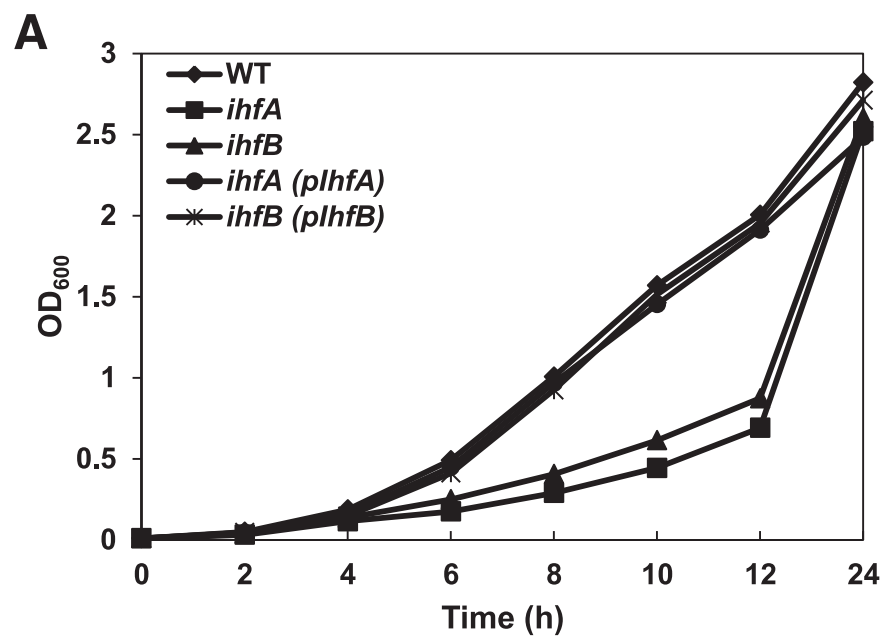

B

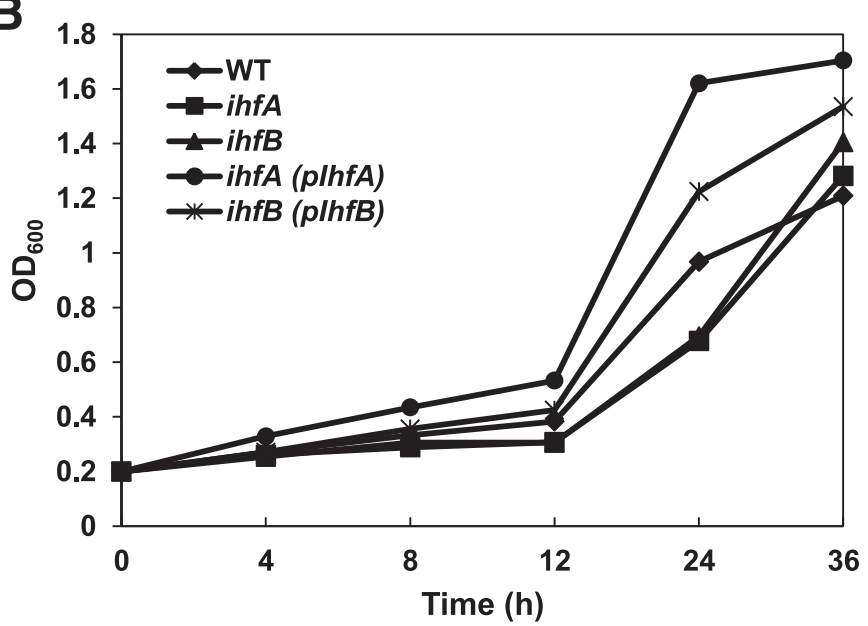

Fig. 1. I integration host factor (IHF) affects growth of Erwinia amylovora under nutrient-rich conditions. The growth $\left(\mathrm{OD}_{600}\right)$ of E. amylovora wild type (WT), the ihfA/ihfB mutants, and their complementation strains was monitored at different time points. A, Luria-Bertani media at $28^{\circ} \mathrm{C}$. B, hrp-inducing medium $(\mathrm{HMM})$ at $18^{\circ} \mathrm{C}$. Data points represent the means of three replicates \pm standard deviation. 
inoculated on immature pear fruits, and disease development was assessed for 8 DPI (Fig. 2A). The WT strain caused water soaking symptoms and bacterial ooze formation at the inoculation site at 4 DPI. The necrotic areas turned black and covered almost the whole pear fruits at $8 \mathrm{DPI}$. However, no disease symptoms were observed for both the ihfA and ihfB mutants; and the virulence of the mutants was partially restored in the complementation strains (Fig. 2A). These results indicate that the ihfA and ihfB genes are required for full virulence of $E$. amylovora.

Bacterial growth of the WT, mutant and complementation strains on immature pear fruits was also quantitatively determined for three days (Fig. 2B). Bacterial number of the WT increased up to $1 \times 10^{9}$ $\mathrm{CFU} / \mathrm{g}$ at 3DPI, and complementation strains showed similar levels of growth as the WT (Fig. 2B). However, the number of the ihfA and $i h f B$ mutants maintained at initial level of inoculum or slightly decreased to $5 \times 10^{3} \mathrm{CFU} / \mathrm{g}$, which represents a six log reduction than that of the WT strain. These results indicate that IHF is required for E. amylovora to colonize and grow on immature pear fruits.

IHF is required for expression of $h r p L$ and other T3SS genes. The effect of mutations in the ihfA and ihfB genes on $h r p L$ and other T3SS gene expressions was examined using qRT-PCR. Expression of T3SS genes, including $d s p E, h r p A, h r p N$, and $h r p L$, was barely detectable in the ihfA and ihfB mutants both in vitro and in vivo (Fig. 3A and B); whereas expression of $h r p S$ was about fivefold lower in the two mutants compared with the WT. These results indicate that IHF is required for expression of the T3SS, via the activation of RpoN-dependent $h r p L$ gene expression.

A

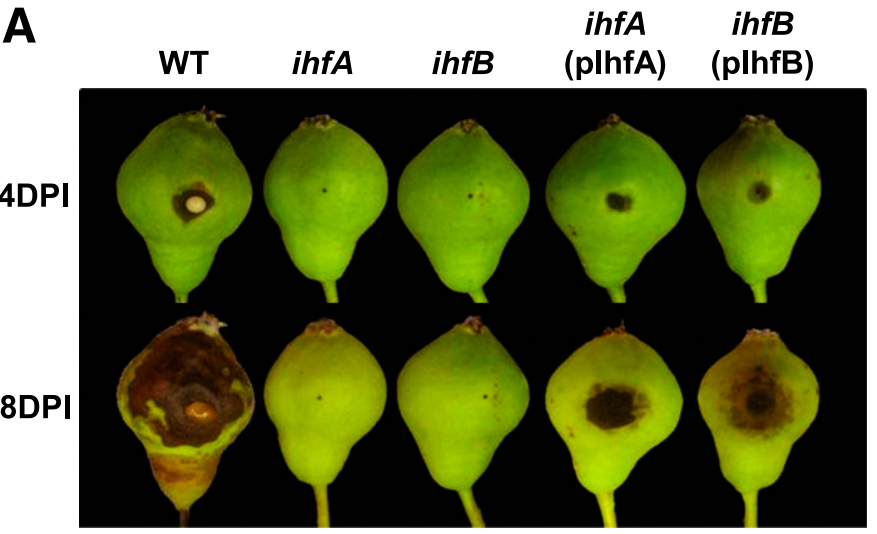

B

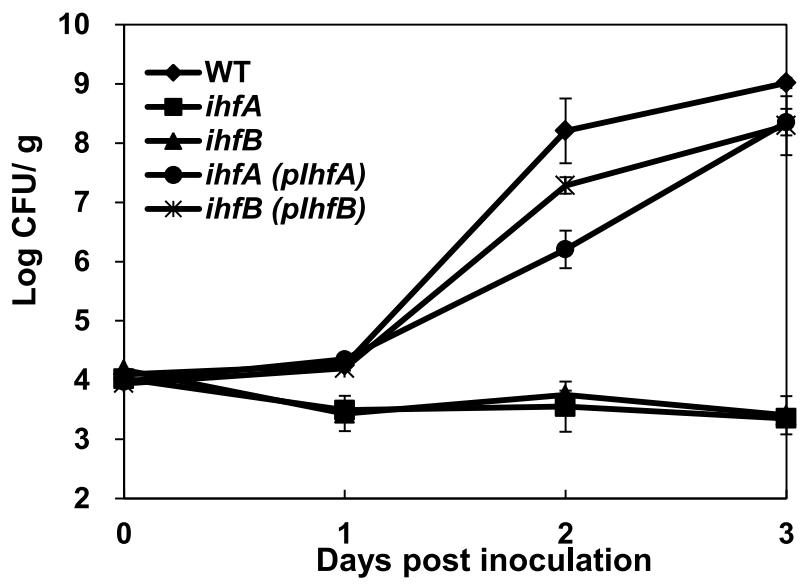

Fig. 2. Virulence assay and bacterial growth of Erwinia amylovora on immature pear fruits. A, Symptoms caused by the wild type (WT), the ihfA/ihfB mutants, and their complementation strains, ihfA (pIhfA) and ihfB (pIhfB). B, Growth of the WT, the $i h f A / i h f B$ mutants, and their complementation strains was monitored at $0,1,2$, and 3 days postinoculation (DPI). Data points represent the means of three replicates \pm standard deviation.
Given that the putative IHF-binding site (TATCAGTGTGTTA) presents in a close proximity to the $h r p L$ promoter (Table 1), binding of IHF to the $h r p L$ promoter was determined by EMSA. We used purified E. coli $\mathrm{IHF} \alpha \beta\left(\mathrm{IHF}_{\mathrm{Ec}}\right)$ heterodimer protein complex (a gift)

A
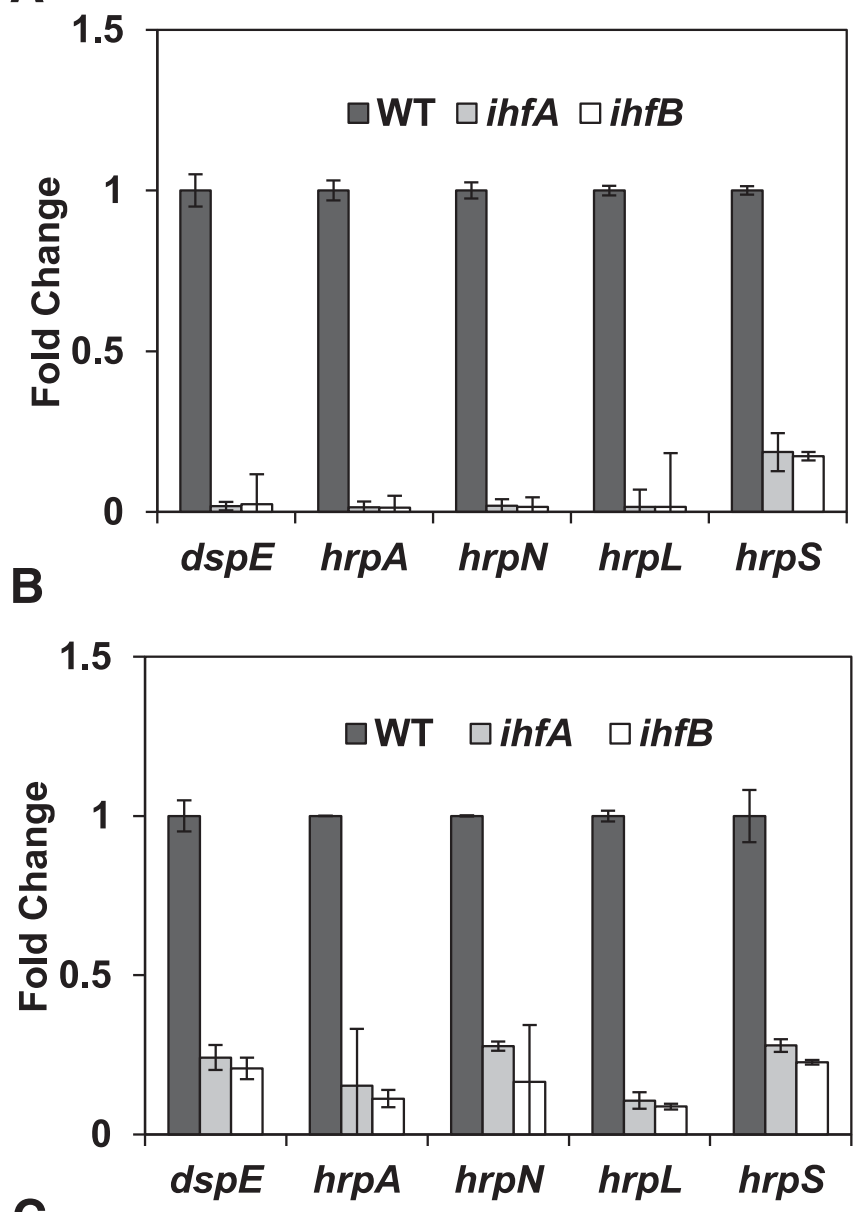

C

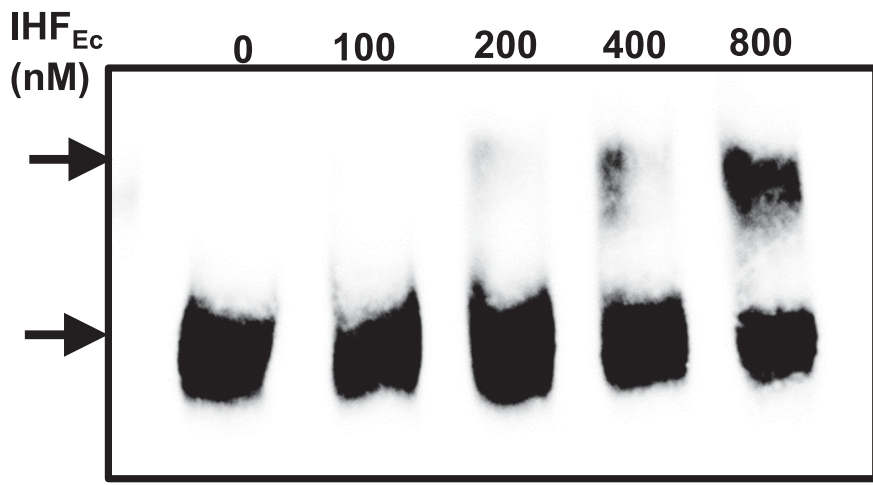

Fig. 3. Integration host factor (IHF) positively controls the expression of the hrptype III secretion system (T3SS) and related regulatory genes by binding to the promoter of the $h r p L$ gene. Relative gene expression of three T3SS genes ( $d s p E$, $h r p A$, and $h r p N$ ) and $h r p L$ and $h r p S$ regulatory genes in the ihfA and ihfB mutants by comparing with those of the wild type (WT) using quantitative real-time reverse transcription-polymerase chain reaction (qRT-PCR). A, hrp-inducing medium at $18^{\circ} \mathrm{C}$ for $6 \mathrm{~h}$ and $\mathbf{B}$, immature pear fruits at $28^{\circ} \mathrm{C}$ for $6 \mathrm{~h}$. The relative fold change of each gene was derived from the comparison of mutant strains versus the WT. The 16S rDNA ( $r r s$ ) gene was used as an endogenous control. The values of the relative fold change were the means of three replicates. Error bars indicate standard deviation. C, Electrophoretic mobility shift assay for a 100-bp fragment of the hrpL promoter sequence was tested for binding to Escherichia coli $\mathrm{IHF}_{\mathrm{Ec}}$ proteins. The protein complex is heterodimers of IhfA and IhfB. Black arrows indicate the free probe (bottom arrow) and the protein-DNA complex (top arrow). The concentration of $\mathrm{IHF}_{\mathrm{Ec}}$ protein was indicated above each lane. 
in our experiment, as both subunits share about 94 to $95 \%$ amino acid identity with the corresponding subunits of E. amylovora. A distinct band shift of the oligonucleotides containing the hrpL upstream sequence ( -146 to $-47 \mathrm{nt}$ ) was observed (Fig. 3C), indicating that IHF binds to the $h r p L$ promoter.

IHF auto-suppresses expression of the $\boldsymbol{i h f A}$ gene. Under both in vitro and in vivo conditions, expression of the ihfA gene was increased about 3- to 15 -fold in the ihfB mutant than those in the WT, whereas expression of the $i h f B$ gene remained unchanged in the ihfA mutant (Fig. 4A and B), suggesting that expression of the ihfA gene is negatively auto-regulated by IHF. Sequence analysis revealed that a potential IHF binding site (AATCAGGTAGTTG) is present in the promoter of the ihfA gene, but not the ihfB gene (Table 1). EMSA results showed that $\mathrm{IHF}_{\mathrm{Ec}}$ binds to the upstream region of the $i h f A$, but not the $i h f B$ gene (Fig. $4 C$ and D). These results indicate that transcription of the ihfA gene is subject to negative autoregulation by IHF.

IHF negatively regulates swimming motility in $E$. amylovora by positively activating $r s m B$ sRNA. Swimming motility of the two single mutants was also compared with that of the WT. Both the ihfA and ihfB mutants exhibited increased circular movement than the WT strain, a phenotype similar to that of the small RNA rsmB mutant as we reported earlier (Fig. 5A and B) (Li et al. 2014). The diameters were about 1.8 and $3.5 \mathrm{~cm}$ for both mutants, and 0.9 and $2.9 \mathrm{~cm}$ for the WT at 24 and $48 \mathrm{~h}$ after incubation, respectively. Complementation of the mutants returned to normal motility as the WT (Fig. 5A and B).These results indicate that IHF negatively regulates swimming motility in E. amylovora.

It has recently been reported that IHF positively regulates $r \operatorname{sm} B$ expression in S. typhimurium (Martínez et al. 2014). Given that mutations of $r s m B$ sRNA and $i h f A / i h f B$ yielded similar motility phenotype, expression of both $r s m B$ sRNA and $r s m A$ of E. amylovora was determined in both the ihfA and ihfB mutants (Fig. 6A). No significant change in $r s m A$ expression was observed, whereas expression of the $r s m B$ sRNA was barely detectable in both the $i h f A$ and $i h f B$ mutants, indicating that IHF positively activates the expression of the $r s m B$ sRNA gene. Sequence analysis revealed a putative IHF-binding site (TATCATCTGGTTA) in the upstream region of the $r s m B$ sRNA (Table 1). EMSA results further confirmed that $\mathrm{IHF}_{\mathrm{Ec}}$ binds to this region (Fig. 6B). These results indicate that IHF might control motility through positively regulating the $r s m B$ sRNA.

\section{DISCUSSION}

Bacterial chromosomal DNA is highly compacted, but organized for genetic activity by small NAPs. The abilities of NAPs to remodel nucleoid structure allow not only the alteration in global gene expression, but also the fine tuning of specific gene expression under various conditions (Dillon and Dorman 2010). NAPs, including IHF, have also been described to modulate gene expression for survival and adaptation to changing environments in many animal and plant pathogenic bacteria (Chatterjee et al. 2002; Jovanovic et al. 2011; Mangan et al. 2006; Porter and Dorman 1997). In this study, we have demonstrated that IHF is required for RpoN-dependent $h r p L$ gene expression and virulence, and controls swimming motility by positively regulating the $r s m B$ sRNA in E. amylovora.

The current model of T3SS regulation in E. amylovora suggests that the T3SS is transcriptionally regulated by an RpoN-HrpL sigma factor cascade, which is further activated by the bacterial alarmone (p)ppGpp (Fig. 7) (Ancona et al. 2014, 2015). In this study, we have demonstrated that IHF, as part of the RpoN complex, including
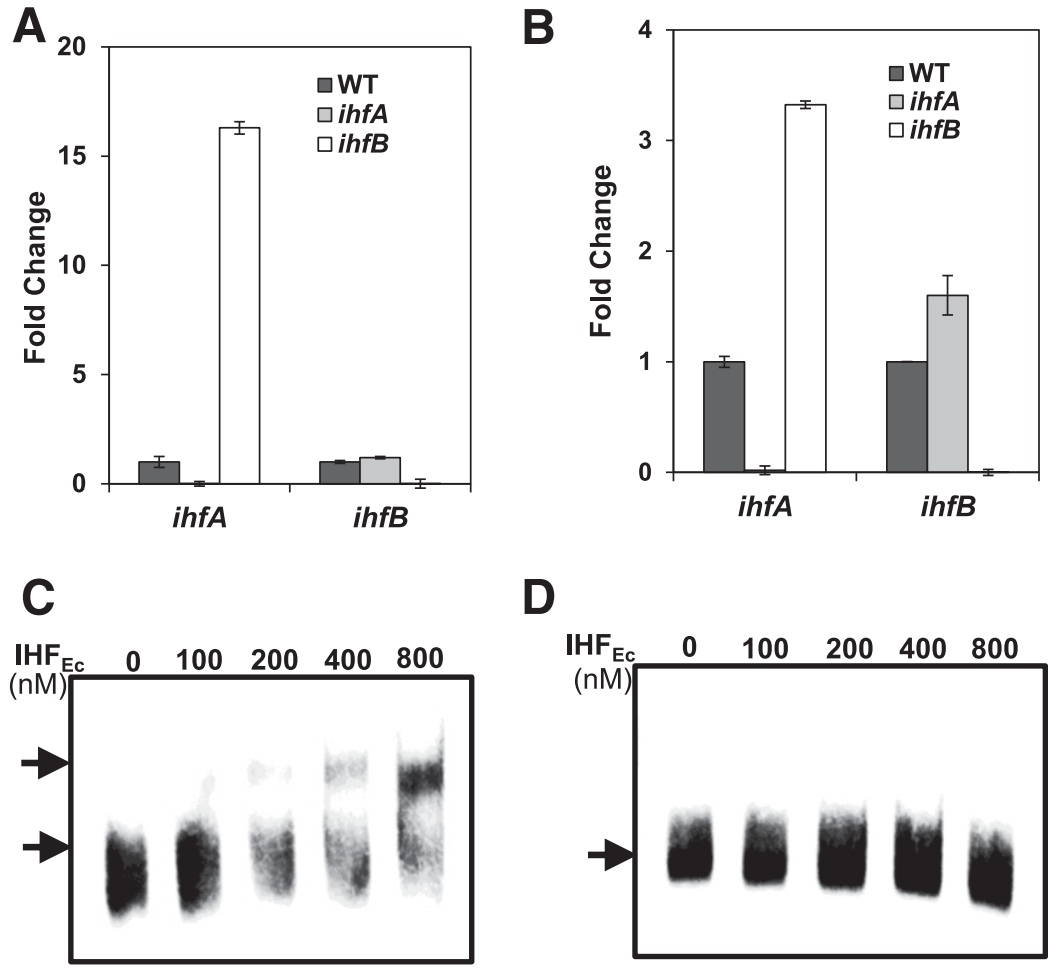

D

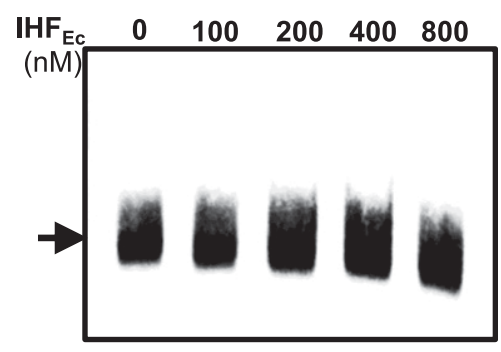

Fig. 4. Integration host factor (IHF) auto-suppresses the expression of the ihfA gene by binding to the promoter of the ihfA gene. Relative gene expression of the $i h f A$ and $i h f B$ genes in the $i h f A$ and $i h f B$ mutants by quantitative real-time reverse transcription-polymerase chain reaction (qRT-PCR) compared with those of the wild type (WT). A, $h r p$-inducing medium at $18^{\circ} \mathrm{C}$ for $6 \mathrm{~h}$, and $\mathbf{B}$, immature pear fruits at $28^{\circ} \mathrm{C}$ for $6 \mathrm{~h}$. The relative fold change of each gene was derived from the comparison of mutant strains versus the WT. The 16S rDNA ( $r r s$ ) gene was used as an endogenous control. The values of the relative fold change were the means of three replicates. Error bars indicate standard deviation. C, Electrophoretic mobility shift assay (EMSA) for a 100-bp fragment of the ihfA promoter sequence; and $\mathbf{D}$, for a 100 -bp fragment of the $i h f B$ upstream sequence were tested for binding to Escherichia coli $\mathrm{IHF}_{\mathrm{Ec}}$ protein complex. The protein complex is heterodimers of IhfA and IhfB. Black arrows indicate the free probe (bottom arrow) and the protein-DNA complex (top arrow). The concentration of $\mathrm{IHF}_{\mathrm{Ec}} \mathrm{Protein}$ was indicated above each lane. 
RpoN, YhbH, and HrpS, directly binds to the upstream region of the $h r p L$ gene (Fig. 7). These findings indicate that IHF-induced DNA bending at the $h r p L$ upstream region might enhance the interaction between HrpS and RpoN-RNAP holoenzyme, which then activates $h r p L$ transcription. In other words, IHF may be required to fully promote the function of $\mathrm{HrpS}$ as an enhancer. It is also possible that the combined effects of IHF in recruiting RpoN-RNAP and facilitating the interaction between HrpS and RpoN-RNAP to ensure that the $h r p L$ gene is one highly IHF/RpoN-dependent gene.

In addition, expression of the $h r p S$ gene was found fivefold lower in the ihfA and ihfB mutants, suggesting that IHF may act as a positive regulator of $h r p S$ expression. HrpS, a member of the $\mathrm{AAA}^{+}$ (ATPases associated with various cellular activities) family of proteins, is believed to play a central role in responding to external stimuli to control T3SS gene expression (Wei et al. 2000). In Pantoea stewartii, multiple environmental cues are sensed by HrpX (sensor kinase) and HrpY (response regulator) two-component system, leading to HrpY-dependent expression of the hrpS gene (Merighi et al. 2003). The putative IHF-binding site is also present at the hrpS promoter region, suggesting that IHFs might be directly involved in the regulation of hrpS expression in P. stewartii (Merighi et al. 2006). However, in E. amylovora, hrpS expression is not dependent upon HrpX/HrpYas previously reported (Wei et al. 2000; Zhao et al. 2009b) and no putative IHF-binding site is present at the upstream region of the $h r p S$ gene (data not shown), indicating that regulation of $h r p S$ in

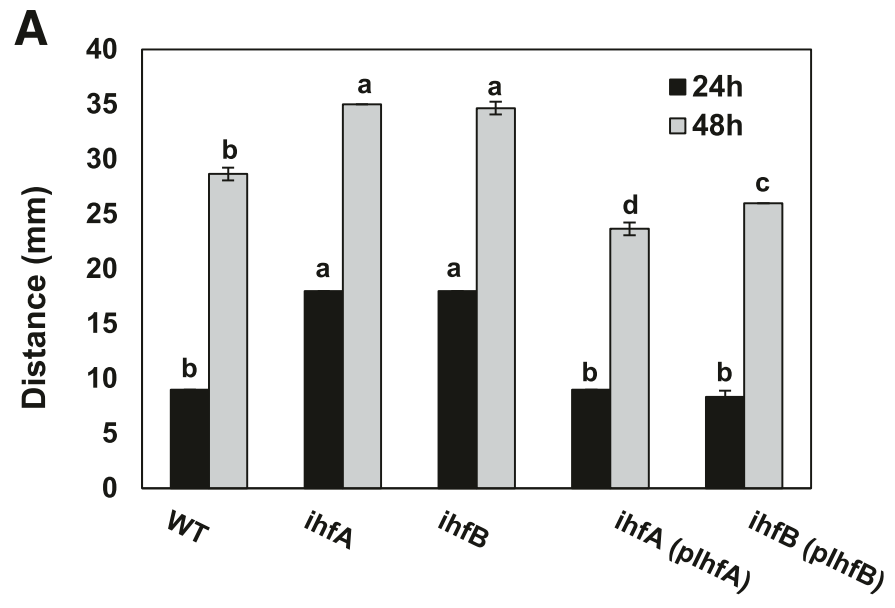

B
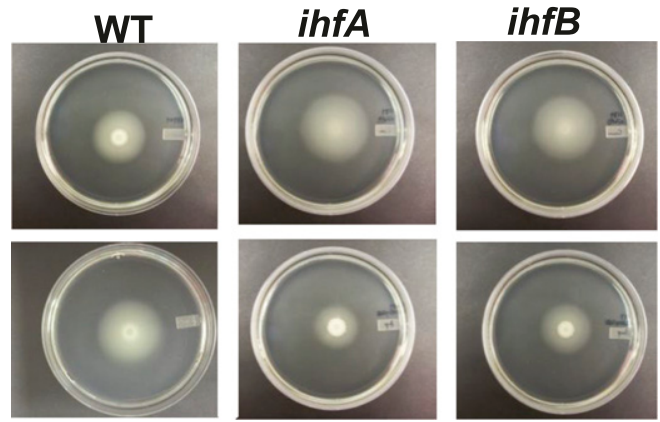

rsmB

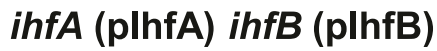

Fig. 5. Integration host factor (IHF) negatively controls swimming motility in Erwinia amylovora. Bacterial strains $\left(\mathrm{OD}_{600}=1.0\right)$ were spotted at the center of the motility plate $\left(0.25 \%\right.$ agar) and incubated at $28^{\circ} \mathrm{C}$. A, The moving distances of the wild type (WT), the ihfA/ihfB mutants, and their complementation strains. Diameters of the circle around the inoculation site $(\mathrm{mm})$ were measured 24 and $48 \mathrm{~h}$ postincubation. One-way analysis of variance and Student's $t$ test $(P=0.05)$ were used to analyze the data. Diameters marked with the same letter are not significantly different $(P<0.05)$. B, Movement of the WT, the ihfA/ihfB mutants, and their complementation strains, as well as the $r s m B$ mutant on the motility plate. Pictures were taken at $48 \mathrm{~h}$ postincubation.
E. amylovora may differ from those in $P$. stewartii, and suggesting that IHF may indirectly regulate $h r p S$ expression through unknown mechanism. Furthermore, it has been proposed that expression of hrpS in E. amylovora is under positive feedback regulation by $\mathrm{HrpL}$ (Ancona et al. 2014), which warrants further investigation.

It has been shown that expression of the ihfA and ihfB genes is controlled by various regulatory mechanisms, including RpoS, ppGpp and autoregulation, as well as by growth stages (Aviv et al. 1994; Ditto et al. 1994). Consistent with previous reports that the abundance of IHF is elevated in the early stationary phase (Azam et al. 1999), IHF $\alpha$ and IHF $\beta$ in E. amylovora also exhibited a similar trend (J. H. Lee and Y. F. Zhao, unpublished data). However, we found that regulation and function of IHF in E. amylovora may differ from those of other members in Enterobacteriacae. In $E$. coli, expression of both the ihfA and ihfB genes is negatively

A
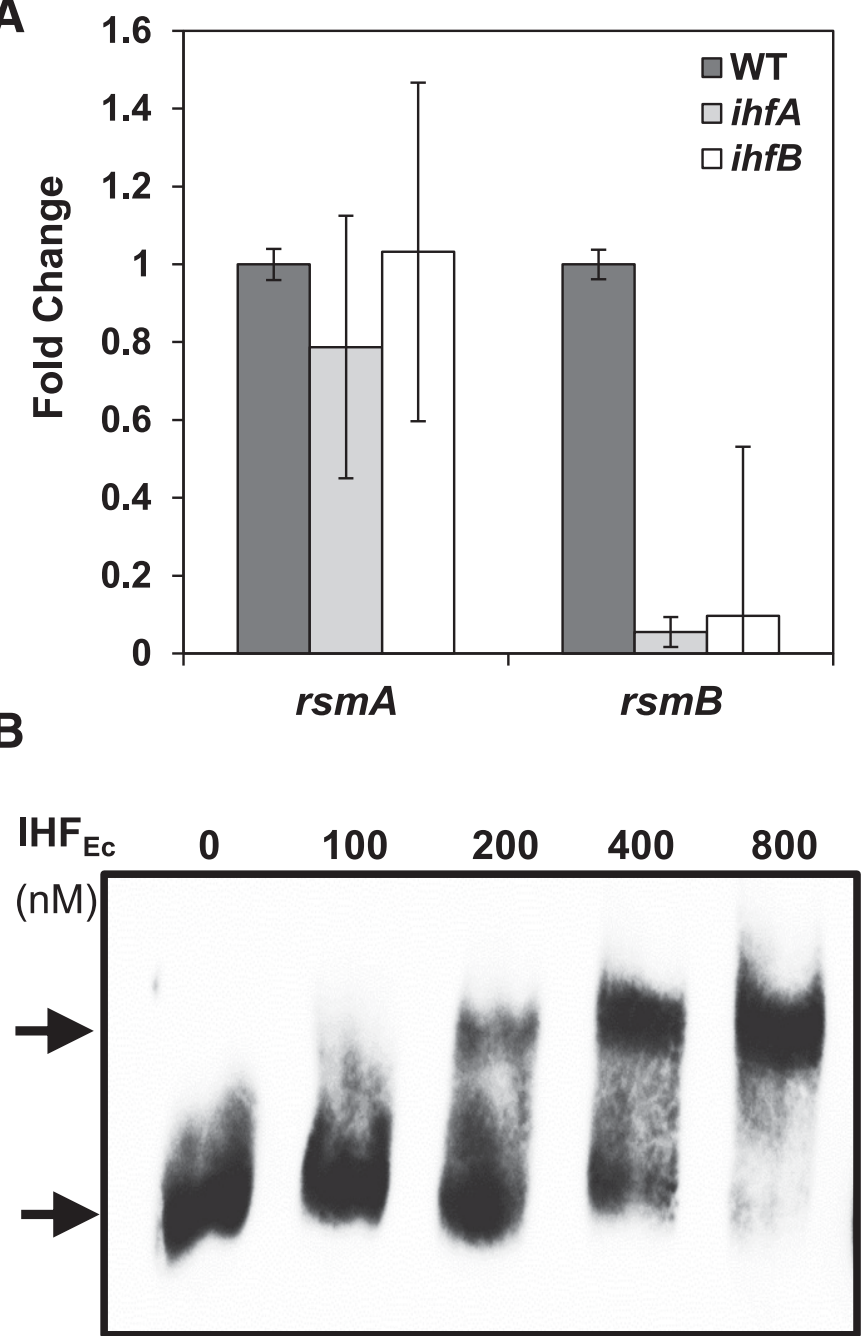

Fig. 6. Integration host factor (IHF) positively activates the $r s m B$ sRNA by binding to the upstream sequence of the $r s m B$ sRNA gene. A, Relative gene expression of the $r s m A$ gene and $r s m B$ sRNA in the ihfA and ihfB mutants compared with those of wild type (WT) grown on immature pear fruits at $28^{\circ} \mathrm{C}$ for $6 \mathrm{~h}$ by quantitative real-time reverse transcription-polymerase chain reaction (qRT-PCR). The relative fold change of each gene was derived from the comparison of mutant strains versus the WT. The $16 \mathrm{~S}$ rDNA ( $r r s$ ) gene was used as an endogenous control. The values of the relative fold change were the means of three replicates. Error bars indicate standard deviation. B, Electrophoretic mobility shift assay for a 100-bp fragment of the $r \operatorname{sm} B$ upstream sequence were tested for binding to Escherichia coli $\mathrm{IHF}_{\mathrm{Ec}}$ protein complex. The protein complex is heterodimers of IhfA and IhfB. Black arrows indicate the free probe (bottom arrow) and the protein-DNA complex (top arrow). The concentration of $\mathrm{IHF}_{\mathrm{Ec}}$ protein was indicated above each lane. 
auto-regulated (Aviv et al. 1994). In contrast, only the ihfA gene is auto-suppressed by IHF in E. amylovora (Fig. 7). In addition, under nutrient-rich conditions, no changes in growth were observed in the ihfA and ihfB mutants of S. typhimurium (Mangan et al. 2006), while deletion of the $i h f A$ and $i h f B$ genes in E. amylovora suppressed bacterial growth, suggesting that the function of IHF in E. amylovora may not be restricted to the stationary phase.

Previous studies have identified many global regulators in E. amylovora, including RcsBCD, EnvZ/OmpR, and GasS/GacA$\mathrm{Rsm} / \mathrm{Csr}$ systems, which control motility by influencing FlhDC, the master regulator of flagellar biosynthesis (Ancona and Zhao 2013; $\mathrm{Li}$ et al. 2014; Zhao et al. 2009b). Among them, GacS/GacA twocomponent system acts as a transcriptional regulator of various cellular processes in $\gamma$-proteobacteria, while $r s m B / c s r B$ is a noncoding regulatory sRNA that binds to RNA-binding protein RsmA/CsrA and regulates its activity (Lapouge et al. 2008). The activated GacA positively regulates the transcription of $r s m B / c s r B$, resulting in the inhibition of posttranscriptional regulator of RsmA/CsrA (Vakulskas et al. 2015). It has been reported that expression of FlhDC is regulated by Gac/Rsm/Csr pathway, through which RsmA/CsrA enhances the stability and translation of $f l h D C$ mRNA from RNase degradation (Wei et al. 2001; Yakhnin et al. 2013). In this study, we found that the hypermotile phenotype of both the ihfA and ihfB mutants was the same as those observed in the gacS/gacA and $r s m B$ mutants (Ancona and Zhao 2013; Li et al. 2014), and that IHF positively regulates $r s m B$ expression by binding to the upstream region of the $\operatorname{rsmB}$ sRNA. These results demonstrated that IHF negatively controls swimming motility by positively regulating the rsmB sRNA as reported in Salmonella (Fig. 7) (Martínez et al. 2014).

In summary, IHF, as global regulators of several DNA-dependent processes, is essential for E. amylovora virulence on host plants. Our results also demonstrated that several virulence traits in E. amylovora, including bacterial growth, T3SS, and motility, are regulated by IHF. We have provided evidence that RpoN-dependent $h r p L$ gene expression requires IHF, which also positively regulates the $\operatorname{rsm} B$ sRNA.

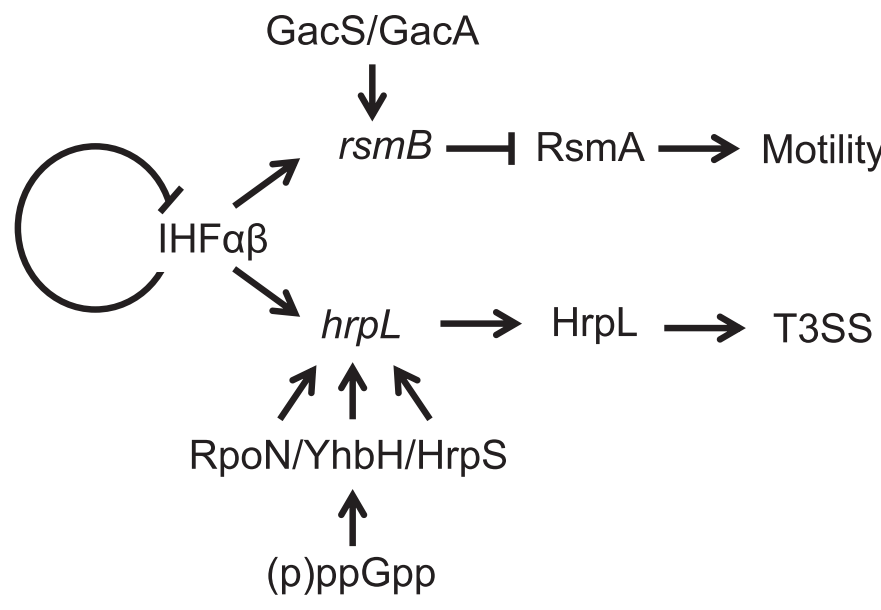

Fig. 7. Working model illustrates the role of integration host factor (IHF) in Erwinia amylovora virulence and motility. This model is based on findings obtained in this study as well as those reported in previously studies (Ancona and Zhao 2013; Ancona et al. 2014, 2015; Li et al. 2014; Zhao et al. 2009b). Symbols: $\downarrow$, positive effect; $\perp$, negative effect; GacS/GacA: two-component regulatory systems; HrpL; an ECF sigma factor and master regulator of T3SS; HrpS: a $\sigma^{54}$-dependent enhancer binding protein; IHF $\alpha \beta$ : integration host factor $\alpha \beta$; (p)ppGpp: linear nucleotide second messengers, i.e., guanosine tetraphosphate (ppGpp) and guanosine pentaphosphate (pppGpp); RpoN: a $\sigma^{54}$ alternative sigma factor; RsmA: RNA-binding protein A; rsmB: small noncoding regulatory RNA; T3SS: type III secretion system; and YhbH: $\sigma^{54}$ modulation protein (ribosome-associated protein).

\section{ACKNOWLEDGMENTS}

We would like to thank Veronica Ancona for her help on the project. This project was supported by the Agriculture and Food Research Initiative Competitive Grants from the USDA National Institute of Food and Agriculture and USDA-Hatch Project ILLU-802-913 (YFZ).

\section{LITERATURE CITED}

Ancona, V., Lee, J. H., Chatnaparat, T., Oh, J., Hong, J. I., and Zhao, Y. F. 2015. The bacterial alarmone (p)ppGpp activates the type III secretion system in Erwinia amylovora. J. Bacteriol. 197:1433-1443.

Ancona, V., Li, W. T., and Zhao, Y. F. 2014. Alternative sigma factor RpoN and its modulator protein $\mathrm{YhbH}$ are indispensable for Erwinia amylovora virulence. Mol. Plant Pathol. 15:58-66.

Ancona, V., and Zhao, Y. F. 2013. CsrA is a positive regulator of virulence factors in Erwinia amylovora. (Abstr.) Phytopathology 103(suppl.):S2.

Aviv, M., Giladi, H., Schreiber, G., Oppenheim, A. B., and Glaser, G. 1994. Expression of the genes coding for the Escherichia coli integration host factor are controlled by growth phase, rpoS, ppGpp and by autoregulation. Mol. Microbiol. 14:1021-1031.

Azam, T. A., Iwata, A., Nishimura, A., Ueda, S., and Ishihama, A. 1999. Growth phase-dependent variation in protein composition of the Escherichia coli nucleoid. J. Bacteriol. 181:6361-6370.

Browning, D. F., Grainger, D. C., and Busby, S. J. W. 2010. Effects of nucleoid-associated proteins on bacterial chromosome structure and gene expression. Curr. Opin. Microbiol. 13:773-80.

Burse, A., Weingart, H., and Ullrich, M. S. 2004. NorM, an Erwinia amylovora multidrug efflux pump involved in in vitro competition with other epiphytic bacteria. Appl. Environ. Microbiol. 70:693-703.

Bush, M., and Dixon, R. 2012. The role of bacterial enhancer binding proteins as specialized activators of $\sigma^{54}$-dependent transcription. Microbiol. Mol. Biol. Rev. 76:497-529.

Chatterjee, A., Cui, Y., and Chatterjee, A. K. 2002. Regulation of Erwinia carotovora hrpL, which encodes an extracytoplasmic function subfamily of sigma factors required for expression of the HRP regulon. Mol. PlantMicrobe Interact. 15:971-980.

Datsenko, K. A., and Wanner, B. L. 2000. One-step inactivation of chromosomal genes in Escherichia coli K-12 using PCR products. Proc. Natl. Acad. Sci. USA 97:6640-6645.

Dillon, S. C., and Dorman, C. J. 2010. Bacterial nucleoid-associated proteins, nucleoid structure and gene expression. Nat. Rev. Microbiol. 8:185-195.

Ditto, M. D., Roberts, D., and Weisberg, R. A. 1994. Growth phase variation of integration host factor level in Escherichia coli. J. Bacteriol. 176:3738-3748.

Goodrich, J. A., Schwartz, M. L., and McClure, W. R. 1990. Searching for and predicting the activity of sites for DNA binding proteins: compilation and analysis of the binding sites for Escherichia coli integration host factor (IHF). Nucleic Acids Res. 18:4993-5000.

Gustave, J. E., Jurcisek, J. A., McCoy, K. S., Goodman, S. D., and Bakaletz, L. O. 2013. Targeting bacterial integration host factor to disrupt biofilms associated with cystic fibrosis. J. Cyst. Fibros. 12:384-389.

Hirschman, J., Wong, P. K., Sei, K., Keener, J., and Kustu, S. 1985. Products of nitrogen regulatory genes $n t r A$ and $n t r C$ of enteric bacteria activate $g \ln A$ transcription in vitro: Evidence that the $n t r A$ product is a sigma factor. Proc. Natl. Acad. Sci. USA 82:7525-7529.

Hunt, T. P., and Magasanik, B. 1985. Transcription of $g \ln A$ by purified Escherichia coli components: core RNA polymerase and the products of $g \ln F, g \ln G$, and $g \ln L$. Proc. Natl. Acad. Sci. USA 82:8453-8457.

Huo, Y. X., Tian, Z. X., Rappas, M., Wen, J., Chen, Y. C., You, C. H., Zhang, X., Buck, M., Wang, Y. P., and Kolb, A. 2006. Protein-induced DNA bending clarifies the architectural organization of the $\sigma^{54}$-dependent $g \ln A p 2$ promoter. Mol. Microbiol. 59:168-180.

Jovanovic, M., James, E. H., Burrows, P. C., Rego, F. G., Buck, M., and Schumacher, J. 2011. Regulation of the co-evolved HrpR and HrpS AAA+ proteins required for Pseudomonas syringae pathogenicity. Nat. Commun. 2:177.

Lapouge, K., Schubert, M., Allain, F. H. T., and Haas, D. 2008. Gac/Rsm signal transduction pathway of $\gamma$-proteobacteria: from RNA recognition to regulation of social behaviour. Mol. Microbiol. 67:241-253.

Li, W., Ancona, V., and Zhao, Y. F. 2014. Co-regulation of polysaccharide production, motility, and expression of type III secretion genes by EnvZ/OmpR and GrrS/GrrA systems in Erwinia amylovora. Mol. Genet. Genomics 289:63-75.

Mangan, M. W., Lucchini, S., Danino, V., Cróinín, T. O., Hinton, J. C. D., and Dorman, C. J. 2006. The integration host factor (IHF) integrates stationaryphase and virulence gene expression in Salmonella enterica serovar Typhimurium. Mol. Microbiol. 59:1831-1847.

Martínez, L. C., Martínez-Flores, I., Salgado, H., Fernández-Mora, M., Medina-Rivera, A., Puente, J. L., Collado-Vides, J., and Bustamante, V. H. 
2014. In silico identification and experimental characterization of regulatory elements controlling the expression of the Salmonella $\operatorname{csr} B$ and $\operatorname{csr} C$ genes. J. Bacteriol. 196:325-336.

McNally, R. R., Toth, I. K., Cock, P. J., Pritchard, L., Hedley, P. E., Morris, J. A., Zhao, Y. F., and Sundin, G. W. 2012. Genetic characterization of the HrpL regulon of the fire blight pathogen Erwinia amylovora reveals novel virulence factors. Mol. Plant Pathol. 13:160-173.

Merighi, M., Majerczak, D. R., Stover, E. H., and Coplin, D. L. 2003. The HrpX/HrpY two-component system activates hrpS expression, the first step in the regulatory cascade controlling the Hrp regulon in Pantoea stewartii subsp. stewartii. Mol. Plant-Microbe Interact. 16:238-248.

Merighi, M., Majerczak, D. R., Zianni, M., Tessanne, K., and Coplin, D. L. 2006. Molecular characterization of Pantoea stewartii subsp. stewartii HrpY, a conserved response regulator of the Hrp type III secretion system, and its interaction with the hrpS promoter. J. Bacteriol. 188:5089-5100.

Miller, H. I., and Friedman, D. I. 1980. An E. coli gene product required for $\lambda$ site-specific recombination. Cell 20:711-719.

Porter, M. E., and Dorman, C. J. 1997. Positive regulation of Shigella flexneri virulence genes by integration host factor. J. Bacteriol. 179:6537-6550.

Ramos, L. S., Lehman, B. L., Sinn, J. P., Pfeufer, E. E., Halbrend, N. O., and McNellis, T. W. 2013. The fire blight pathogen Erwinia amylovora requires the rpoN gene for pathogenicity in apple. Mol. Plant Pathol. 14:838-843.

Sambrook, J., and Russel, D. W. 2001. Molecular Cloning: A Laboratory Manual. Cold Spring Harbor Laboratory, Cold Spring Harbor, NY.

Schumacher, J., Joly, N., Rappas, M., Zhang, X., and Buck, M. 2006. Structures and organisation of AAA+ enhancer binding proteins in transcriptional activation. J. Struct. Biol. 156:190-199.

Sebaihia, M., Bocsanczy, A. M., Biehl, B. S., Quail, M. A., Perna, N. T., Glasner, J. D., DeClerck, G. A., Cartinhour, S., Schneider, D. J., Bentley, S. D., Parkhill, J., and Beer, S. V. 2010. Complete genome sequence of the plant pathogen Erwinia amylovora strain ATCC 49946. J. Bacteriol. 192:2020-2021.

Swinger, K. K., and Rice, P. A. 2004. IHF and HU: flexible architects of bent DNA. Curr. Opin. Struct. Biol. 14:28-35.

Vakulskas, C. A., Potts, A. H., Babitzke, P., Ahmer, B. M., and Romeo, T. 2015. Regulation of bacterial virulence by Csr (Rsm) systems. Microbiol. Mol. Biol. Rev. 79:193-224.
Wang, D., Korban, S. S., and Zhao, Y. F. 2010. Molecular signature of differential virulence in natural isolates of Erwinia amylovora. Phytopathology 100:192-198.

Wang, D., Qi, M., Calla, B., Korban, S. S., Clough, S. J., Cock, P. J., Sundin, G. W., Toth, I., and Zhao, Y. F. 2012. Genome-wide identification of genes regulated by the Rcs phosphorelay system in Erwinia amylovora. Mol. Plant-Microbe Interact. 25:6-17.

Wei, B. L., Brun-Zinkernagel, A. M., Simecka, J. W., Prüss, B. M., Babitzke, P., and Romeo, T. 2001. Positive regulation of motility and flhDC expression by the RNA-binding protein CsrA of Escherichia coli. Mol. Microbiol. 40:245-256.

Wei, Z. M., and Beer, S. V. 1995. hrpL activates Erwinia amylovora hrp gene transcription and is a member of the ECF subfamily of sigma factors. J. Bacteriol. 177:6201-6210.

Wei, Z. M., Kim, J. F., and Beer, S. V. 2000. Regulation of hrp genes and type III protein secretion in Erwinia amylovora by HrpX/HrpY, a novel twocomponent system, and HrpS. Mol. Plant-Microbe Interact. 13:1251-1262.

Yakhnin, A. V., Baker, C. S., Vakulskas, C. A., Yakhnin, H., Berezin, I., Romeo, T., and Babitzke, P. 2013. CsrA activates flhDC expression by protecting flhDC mRNA from RNase E-mediated cleavage. Mol. Microbiol. 87:851-866.

Yang, F., Korban, S. S., Pusey, L., Elofsson, M., Sundin, G. W., and Zhao, Y. F. 2014. Small molecule inhibitors suppress expression of both type III secretion and amylovoran biosynthesis genes in Erwinia amylovora. Mol. Plant Pathol. 15:44-57.

Zhao, Y. F. 2014. Genomics of Erwinia amylovora and related species associated with pome fruit trees. Pages 1-36 in: Genomics of plant-associated bacteria. D. C. Gross, A. Lichens-Park, and C. Kole, eds. Springer, New York, NY.

Zhao, Y. F., Sundin, G. W., and Wang, D. 2009a. Construction and analysis of pathogenicity island deletion mutants of Erwinia amylovora. Can. J. Microbiol. 55:457-464.

Zhao, Y. F., Wang, D., Nakka, S., Sundin, G. W., and Korban, S. S. 2009b. Systems level analysis of two-component signal transduction systems in Erwinia amylovora: Role in virulence, regulation of amylovoran biosynthesis and swarming motility. BMC Genomics 10:245. 